\title{
ANÁLISE DA CULTURA DA ERVA-MATE COMO ALTERNATIVA SOCIAL, ECONÔMICA E AMBIENTAL PARA COMUNIDADES RURAIS
}

\author{
Marli Salete Antoniazzi ${ }^{1}$ \\ Lisiane Dörr Rocha ${ }^{2}$ \\ Eduardo Lorensi Souza ${ }^{3}$ \\ Divanilde Guerra ${ }^{4}$ \\ Danni Maisa Da Silva ${ }^{5}$ \\ Marciel Redin ${ }^{6}$
}

Resumo: A erva-mate (Ilex paraguariensis) é uma planta típica do Rio Grande do Sul, faz parte da história e tem possibilidade de ser cultivada em pequenas propriedades rurais, com retornos econômico, social, bem como para preservação do meio ambiente. O presente trabalho teve por objetivo através de ação de extensão com palestras e questionários, analisar a percepção do cultivo da erva-mate como alternativa para recuperação de áreas degradadas no meio rural e, sua importância econômica e social para estudantes do ensino fundamental de quatro comunidades rurais do município de Três Passos - RS. Antes do início da palestra em cada comunidade foi aplicado um questionário para diagnóstico sobre o conhecimento dos estudantes em relação a erva-mate, desde o seu cultivo, benefícios, até a preocupação com áreas degradadas. Os resultados obtidos mostraram pouco conhecimento em relação ao cultivo e benefícios da erva-mate, embora seja encontrada no município. Ainda, os estudantes relatam grande preocupação com áreas degradadas e interesse no cultivo da erva-mate. Assim, o cultivo da erva-mate poderá ser uma alternativa a ser buscada para os futuros produtores das comunidades rurais que enfrentam dificuldades em obter soluções de ampliação e diversificação de renda em suas propriedades rurais. Aliado a isso, de uma forma simples, mas que vem ao encontro de soluções que levem em conta os impactos sociais e ambientais, o cultivo da erva-mate pode garantir o bem-estar e a permanência dos jovens no campo do município de Três Passos - RS.

Palavras-chave: ação de extensão, Ilex paraguariensis; meio ambiente; sustentabilidade.

ABSTRACT: The yerba mate (Ilex paraguariensis) is a typical plant of Rio Grande do Sul, is part of the history and has the possibility of being cultivated in small farms with economic, social and environmental preservation. The objective of the present work was to extend the knowledge of the cultivation of mate-grass as an alternative for the recovery of degraded areas in rural areas and its economic and social importance for elementary school students in four communities of the municipality of Três Passos - RS. Before the start of the lecture in each community, a questionnaire was applied to diagnose the students' knowledge about yerba mate,

\footnotetext{
1 Tecnóloga em Administração Rural pela UFRGS. Acadêmica do Curso de Especialização em Gestão e Sustentabilidade Ambiental, UERGS Unidade Três Passos, RS.

2 Tecnóloga em Administração Rural pela UFRGS. Acadêmica do Curso de Especialização em Gestão e Sustentabilidade Ambiental, UERGS Unidade Três Passos, RS

${ }^{3}$ Professor da Universidade Estadual do Rio Grande do Sul - UERGS, Unidade Três Passos, RS.

${ }^{4}$ Professor da Universidade Estadual do Rio Grande do Sul - UERGS, Unidade Três Passos, RS

${ }^{5}$ Professor da Universidade Estadual do Rio Grande do Sul - UERGS, Unidade Três Passos, RS.

${ }^{6}$ Professor da Universidade Estadual do Rio Grande do Sul - UERGS, Unidade Três Passos, RS
} 
from its cultivation, benefits, to the concern with degraded areas. The results obtained showed little knowledge regarding the cultivation and benefits of yerba mate, although it is found in the municipality. Still, the students report great concern about degraded areas and interest in the cultivation of yerba mate. Thus, the cultivation of yerba mate may be an alternative to be sought for future producers of rural communities who face difficulties in obtaining solutions to increase and diversify income on their rural properties. Allied to this, in a straightforward way, but that comes to the encounter of solutions that consider the social and environmental impacts, the cultivation of the yerba mate can guarantee the well-being and the permanence of the youth in the field of the municipality of Três Passos - RS.

Keywords: Extension action, Ilex paraguariensis; environment; sustainability.

\section{INTRODUÇÃO}

Nos últimos anos a maior preocupação está voltada para o meio ambiente, principalmente nas causas que levam aos impactos ambientais decorrentes das atividades antrópicas. A escolha de práticas quanto à preservação depende do nível cultural e conhecimento, além dos aspectos ambientais de cada propriedade rural. Desta forma, os personagens principais são os agricultores e seus familiares que tem um importante papel na ação da busca por uma vida saudável e o uso consciente do meio ambiente. A conservação do meio ambiente mantém a capacidade produtiva dos solos, o aumento da diversidade e produção das culturas garantindo, assim o ecossistema equilibrado para a atual e as futuras gerações (EMBRAPA, 2011).

Nesse contexto, a espécie Ilex paraguariensis (Aquifoliaceae), popularmente conhecida como erva-mate surge como uma alternativa, além de prevenir possíveis impactos ambientais, permite a ampliação da fonte de renda das famílias rurais com a venda da erva-mate in natura ou processada, desempenhando um importante papel socioeconômico (BERNARDI et al., 2005). A erva-mate tem a capacidade de sobrevivência no bioma da Mata Atlântica até 30 ou 40 anos (OLIVEIRA; WAQUIL, 2014). Isso pode ser traduzido como uma fonte de renda a longo prazo aos produtores rurais, contribuindo para a permanência das famílias no campo. Historicamente, a erva-mate tem sido fundamental para a economia de muitos municípios do Sul do Brasil e, atualmente, é o principal produto não madeireiro do agronegócio florestal na Região Noroeste do RS (EMBRAPA, 2015). Assim, o cultivo da erva-mate é de grande importância, pois representa um relevante instrumento de inclusão social, principalmente na agricultura familiar (ANTONIAZZI, 2013).

Ainda, o cultivo da erva-mate apresenta considerável importância na regeneração de nascentes, recuperação de áreas degradadas e da mata ciliar em propriedades rurais, podendo Revista Extensão em Foco, nº 15, Jan/ Jul, p.108 - 119, 2018. 
assim, amenizar impactos ambientais decorrentes do uso intensivo do solo pela agricultura (PASINATO, 2003). Nessa temática, algumas ações de pesquisa e/ou extensão, envolvendo universidades, órgãos de extensão, em parceria com pesquisadores da Embrapa estão sendo desenvolvidas no setor ervateiro, porém são trabalhos limitados. Nesse sentido, a iniciativa de aumentar o grau de conhecimento e difusão do cultivo da erva-mate requer a necessidade de desenvolvimento de tecnologias ao setor ervateiro, e principalmente ações de extensão.

No município de Três Passos entre os anos 2005 a 2015 ocorreu uma redução na área plantada, e consequentemente, a oferta de matéria prima para a indústria da erva-mate, que por esse motivo, leva a busca da matéria prima em outros municípios da região. Embora, seja notória a importância social, econômica e ambiental do cultivo de erva-mate, conforme por exemplo, relatado por Oliveira; Waquil (2014), é necessária maior divulgação do cultivo da erva-mate através dos meios de comunicação, políticas públicas voltadas para o segmento do cultivo da erva-mate, e principalmente, nas propriedades e ambientes escolares rurais. Nesse sentido, no município de Três Passos - RS existe o projeto chamado de Programa Semeando Educação e Saúde na Agricultura Familiar (SEMEANDO), em parceria com a Secretaria da Educação e Universidade Estadual do Rio Grande do Sul - UERGS, proporciona aos filhos de agricultores em idade escolar, uma educação baseada na formação e desenvolvimento integral do indivíduo. Esse incentiva atividades que possam contribuir para a permanência dos jovens no campo, e assim, sucessores na propriedade agrícola (TRÊS PASSOS, 2011). O projeto semeando promove palestras, minicursos e dias de campo temáticos com estudantes, professores, produtores e público em geral do meio rural com o objetivo de manter um diálogo mais próximo junto às comunidades das escolas rurais do município.

Neste contexto, a divulgação do cultivo da erva-mate, busca integrar a sociedade escolar no todo, para alternativas que venham ao encontro à realidade vivida pelos estudantes, no seu cotidiano no meio rural com o propósito de encontrar meios que possam ser amenizados os impactos ambientais bem como uma alternativa de renda para estas famílias. Assim, o objetivo deste trabalho foi analisar a percepção da erva-mate como alternativa para a recuperação de nascentes, áreas degradadas no meio rural, sua importância econômica e social para estudantes e agricultores familiares, além de realizar a difusão do cultivo da cultura no município de Três Passos - RS.

\section{MATERIAL E MÉTODOS}

Revista Extensão em Foco, nº 15, Jan/ Jul, p.108 - 119, 2018. 
As atividades, na forma de palestras sobre o cultivo da erva-mate, foram realizadas em quatro escolas de diferentes comunidades rurais do município de Três Passos RS, totalizando 39 participantes, estudantes filhos dos agricultores familiares. Ainda, as palestras foram complementadas com vídeos temáticos e também realizada a distribuição de mudas de ervamate para todos os estudantes participantes, doadas pela Secretaria do Meio Ambiente do município de Três Passos. Os estudantes fazem parte do "Programa Semeando" com disciplinas específicas voltadas para a Gestão Ambiental, do oitavo e nono ano das escolas de ensino fundamental do interior do município. As atividades, totalizando quatro dias no mês de setembro de 2016, foram realizadas em quatro dias consecutivos, com uma palestra em cada escola. As escolas participantes foram, Guia Lopes na comunidade da Floresta, Dom João Becker na Linha Santo Antônio, Bispo Pedro Fernandes Sardinha na comunidade Barra da Romana e Wally Elisa Hartmann na comunidade Alto Erval Novo.

A pesquisa exploratória com questionários foi realizada com aos estudantes participantes antes e após a realização de cada palestra nas escolas sobre cultivo da erva-mate como alternativa para, regeneração de nascentes e recuperação de áreas degradadas, além de alternativa de renda no meio rural. O questionário inicial, ou seja, aplicado antes da realização das palestras em cada escola foi constituído de 13 questões com o propósito de realizar um diagnóstico de conhecimento inicial sobre o cultivo de erva-mate, e seu retorno econômico, social e ao meio ambiente. Com o propósito de verificar o aprendizado dos estudantes, ao final da realização das palestras nas escolas, foi aplicado um outro questionário, porém com cinco questões.

Ainda, foi aplicado um questionário com questões direcionado a um proprietário de ervateira denominada "Erva Mate Celeiro Três Passos" com o propósito de fazer um diagnóstico e estudo de caso referente ao cultivo da erva-mate nas seguintes temáticas: por que da opção em cultivar a erva-mate e não a produção de grãos; tamanho da propriedade com o cultivo de erva-mate; onde é adquirida a matéria prima, local ou regional; qual a capacidade de industrialização de matéria prima mês tem a agroindústria; quais são seus clientes e, seu ponto de vista sobre o cultivo de erva-mate como uma alternativa para a preservação do meio ambiente.

As respostas obtidas nos questionários das palestras com os estudantes e no estudo de caso foram descritas através de análises descritivas ou gráficas para a melhor visualização dos resultados.

\section{RESULTADOS E DISCUSSÕES}

Revista Extensão em Foco, nº 15, Jan/ Jul, p.108 - 119, 2018. 
A faixa etária do público participante foi de 13 a 18 anos, estudantes do ensino fundamental das escolas e filhos dos agricultores familiares das quatro comunidades rurais. Observou-se maior participação de estudantes do sexo masculino (62\%), comparado os do sexo feminino (38\%). Tal resultado, de acordo com Maurina (2011), pode-se indicar a alta taxa de êxodo rural das mulheres, principalmente daqueles da agricultura familiar, mesmo de idade escolar, principalmente os jovens. Diante disso, as crianças e a juventude na área rural estão recebendo notória atenção, tendo em vista a sua importância para a sustentabilidade no meio rural. Ainda, de acordo com Maurina (2011), a busca por oportunidades de estudo e trabalho pelos jovens nas cidades causou mudanças na estrutura social das comunidades rurais, assim como impactos sobre vários aspectos culturais, sociais e econômicos.

A principal motivação para a participação nas atividades foi a busca pela informação e conhecimento, além da notável importância do tema nos últimos anos, relatam os estudantes participantes do estudo. De acordo com EMBRAPA (2014), a disputa com outras espécies vegetais, como a soja, trigo e milho, a deficiência de mão-de-obra no meio rural, entre outros fatores, causa incertezas aos agentes econômicos que compõe a cadeia agroindustrial. Nesse sentido, atualmente, através de pesquisas, está evidente que o cultivo da erva-mate pode ser uma das alternativas para promover a sustentabilidade das pequenas propriedades rurais.

A maioria dos estudantes nunca havia participado de palestras referente ao cultivo de erva-mate (90\%). Esse resultado pode evidenciar, embora a erva-mate é encontrada na região, não há o conhecimento específico quanto ao cultivo da erva-mate e seus benefícios com o meio ambiente. Essa constatação fica evidente na figura $1 \mathrm{~A}$, onde $77 \%$ dos estudantes não tinham conhecimento referente ao cultivo da erva-mate. Em contrapartida, 95\% dos estudantes conhecem os benefícios que a erva-mate oferece na recuperação de nascentes, áreas degradadas, reflorestamento da mata ciliar e dos benefícios em geral que a cultura oferece em favor do meio ambiente (Figura 1B). 

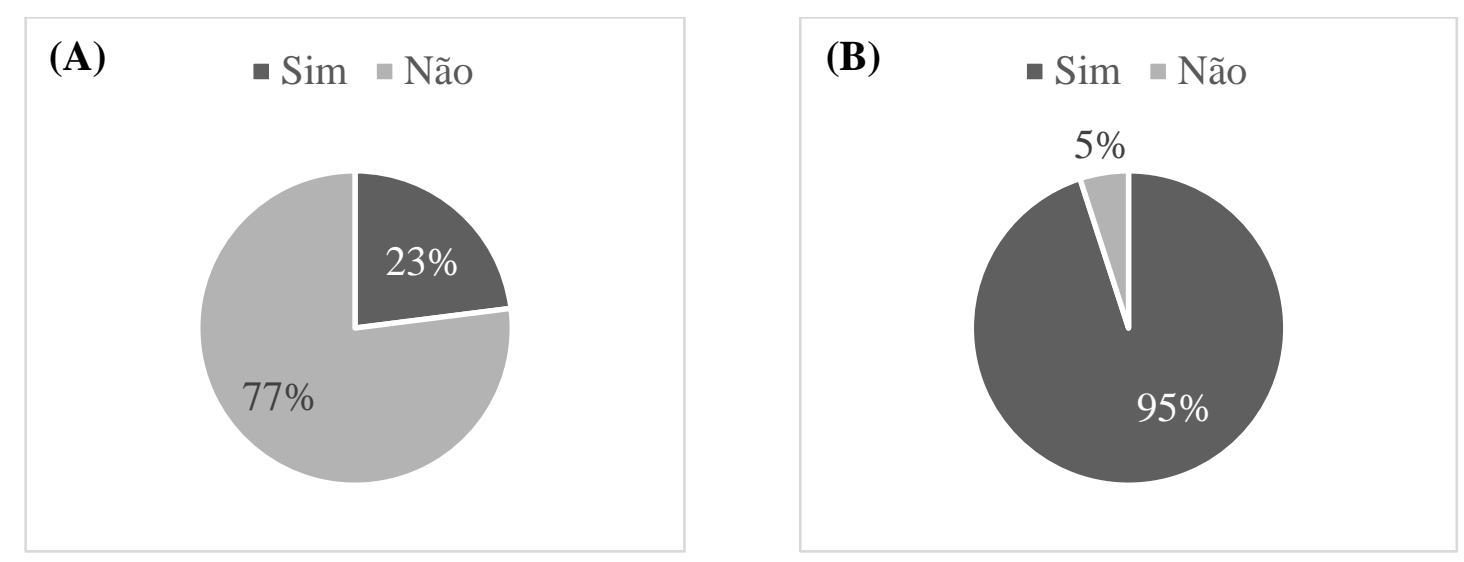

Figura 1 - Conhecimento inicial dos estudantes da pesquisa sobre o cultivo (A) e benefícios (B) do cultivo da erva-mate em Três Passos/RS, 2017. Fonte: Dados dos pesquisadores (2017).

Segundo EMBRAPA (2015), propostas ou ações com o cultivo da erva-mate possibilitam conter impactos ambientais nas pequenas propriedades rurais, que atualmente são visíveis e causadas pela falta de arborização e, que venham de encontro às necessidades por soluções que motivem a regeneração dos meios naturais. Essas áreas quando preservadas conservam a qualidade e o suprimento das águas, mantendo estável a proteção dos solos contra a erosão e assoreamento de rios e riachos, bem como o controle da estabilidade ambiental associado à fauna e a flora. De acordo com Pasinato (2003), a erva-mate pode representar um auxílio no equilíbrio dos ecossistemas locais, pois aceita o sistema de consórcio com outras plantas, devido ao seu caráter nativo presente na mata atlântica e, assim, preserva a entomofauna local, auxiliando no equilíbrio do Agroecossistema e consequentemente, à melhoria da qualidade de vida dos agricultores que desenvolvem esta atividade.

O cultivo da erva-mate apresenta boa tolerância a solos com baixa fertilidade natural e degradados (VIEIRA, 2012). De acordo com EMBRAPA (2013), a cultura da erva-mate aumenta a infiltração da água das chuvas, pois forma uma barreira vegetal que reduz o escorrimento superficial e seu sistema de raízes é mais profundo que o de culturas de grãos ou pastagens. Por outro lado, em relação a preocupação aos impactos ambientais de uma área degradada, um número menor dos estudantes que se preocupam com as suas causas, bem como os que não tem essa preocupação envolvendo o meio ambiente (apenas 33\%) (Figura 2A). Observa-se que atualmente, há uma grande resistência por parte dos agricultores quanto à recuperação de nascentes e áreas degradadas e até mesmo com cuidados a mata ciliar, especialmente quando for necessário dispor de tempo para cuidados com as mudas das árvores plantadas ou principalmente quando há necessidade de investimento econômico. No entanto, de acordo com Carpenazzi; Santarosa (2016), proteger a mata nativa é também preservar a propriedade, a produção, a água 
e, consequentemente o meio ambiente. Atualmente, busca-se caminhos para recuperação de áreas degradadas, a partir de proposições de métodos com baixo custo, mas com restituição financeira, ou seja, associar a recuperação a partir da integração entre a produção e a preservação ambiental de suas propriedades. Neste sentido o cultivo da erva-mate vem de encontro de soluções buscadas por meios de sistemas agroflorestais para a proteção de áreas em degradação no meio rural.
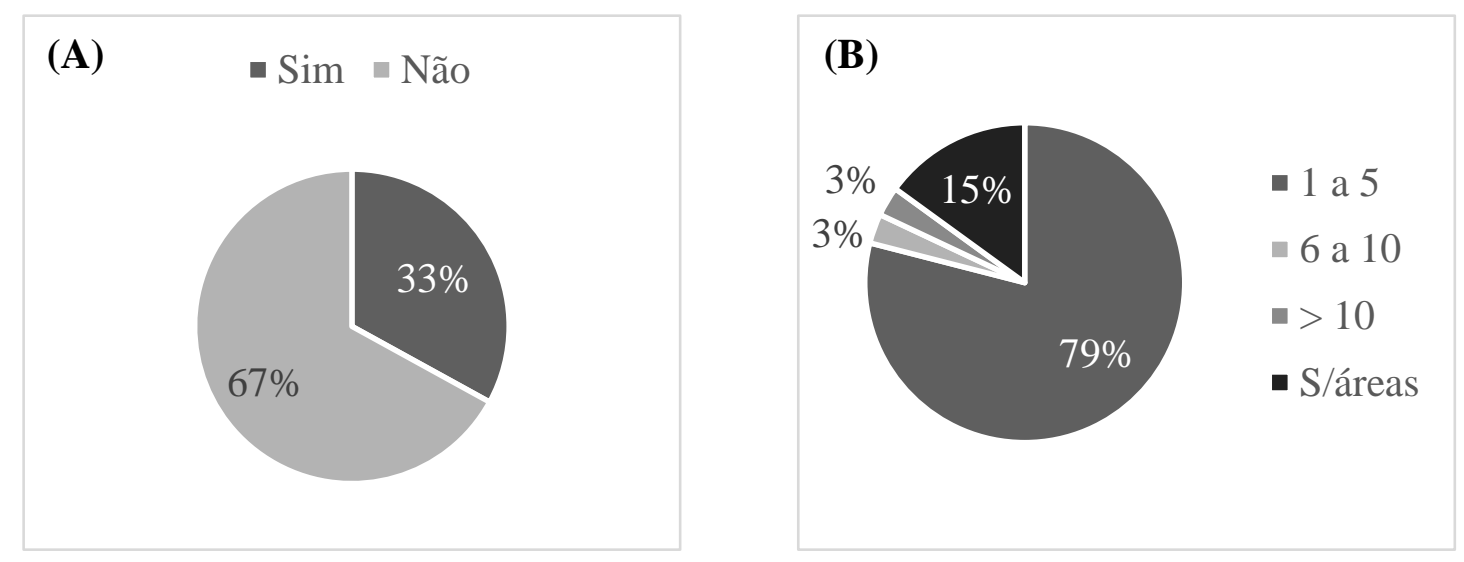

Figura 2 - Preocupação dos estudantes com áreas degradadas (A) e problemas com áreas degradadas (B), em Três Passos/RS, 2017. Fonte: Dados dos pesquisadores (2017).

O tamanho médio das propriedades relatadas pelos estudantes são áreas de até 5 hectares (25\%), 6-10 hectares (26\%) e maior que 10 hectares (49\%). Nas referidas propriedades os estudantes relataram que $79 \%$ apresentam de 1 a 5 hectares com problemas de áreas ou nascentes com necessidade de serem recuperadas (Figura 2B) e 54\% recebem assistência técnica, como por exemplo da EMATER-RS (Figura 3A). Entre os estudantes, 72\% demonstraram interesse em cultivar erva-mate com o objetivo de recuperar nascentes, áreas degradas ou mata ciliar, e obter uma fonte de renda com a cultura (Figura 3B). Desta forma, de acordo com EMBRAPA (2010) o uso da erva-mate é uma importante alternativa para recuperação dessas áreas degradadas usada em sistema solteiro ou agroflorestal, além do retorno financeiro com a venda da erva-mate. 

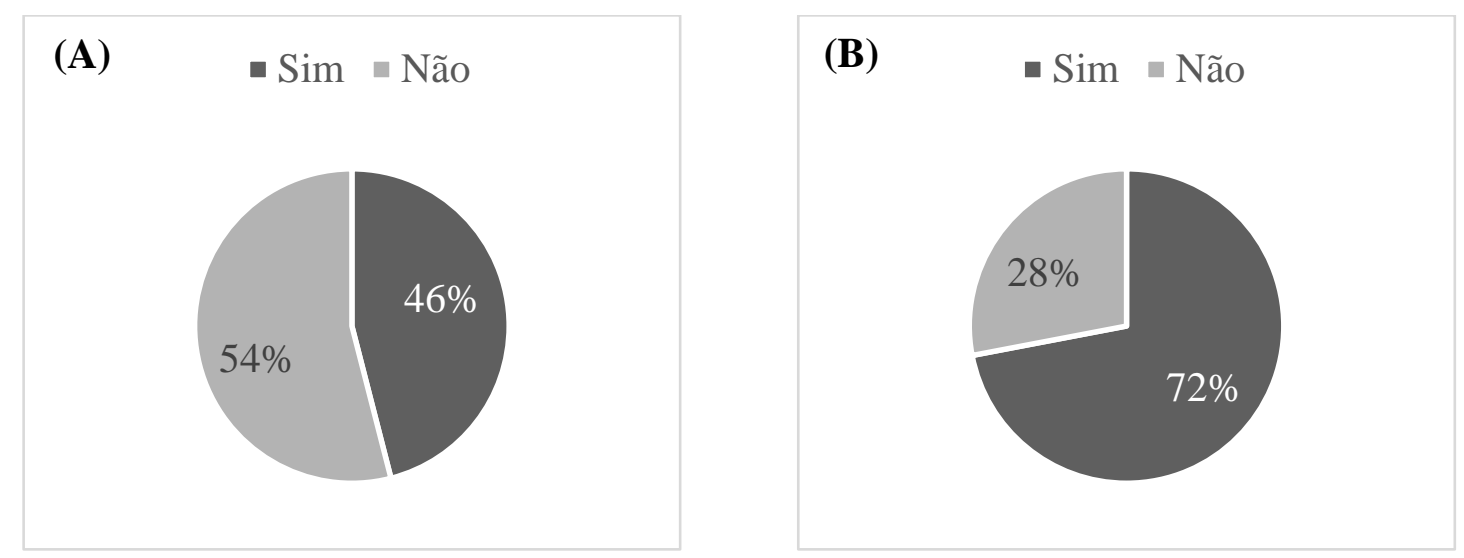

Figura 3 - Assistência técnica nas propriedades (A) e interesse dos estudantes no cultivo da erva-mate (B), em Três Passos/RS, 2017. Fonte: Dados dos pesquisadores (2017).

Após a realização das atividades sobre cultivo da erva-mate, 95\% dos estudantes relatam que o evento atendeu aos objetivos iniciais esperados (Figura 4A). Como consequência observou-se que, todos os estudantes das palestras foram unânimes em responder que é importante o cultivo da erva-mate e seus benefícios como alternativas de recuperação de áreas degradadas, mata ciliar e a possibilidade extra de fonte de renda (Figura 4B).
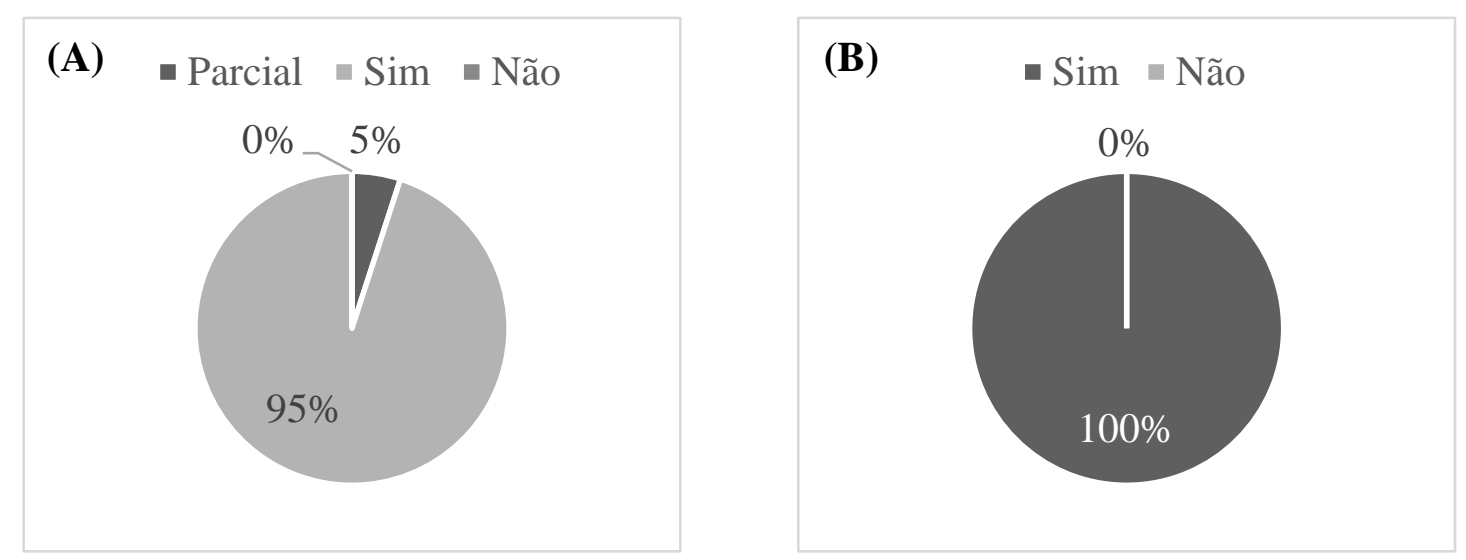

Figura 4 - Atendimento dos objetivos iniciais dos estudantes sobre as atividades propostas (A) e importância do cultivo da erva-mate (B), em Três Passos/RS, 2017. Fonte: Dados dos pesquisadores (2017).

Segundo Berkai; Braga (2000), no RS, algumas regiões do estado em que a erva-mate é uma das grandes economias, como por exemplo, o município de Heliópolis, onde este é considerado a capital da erva-mate, os agricultores sobrevivem unicamente com a produção desta cultura. De acordo com Correa et al. (2011), a cultura da erva-mate e o hábito de beber chimarrão desempenham importante papel econômico e sociocultural na região sul do Brasil, 
sendo essa bebida considerada um forte instrumento de socialização do povo sulino, e o cultivo e a industrialização da erva, mate uma importante alternativa econômica à agricultura familiar desses estados. De acordo com Vieira, et al. (2008), até pouco tempo o setor ervateiro dependia quase que exclusivamente da comercialização da erva-mate na sua forma tradicional de chimarrão, o que limitava o mercado às regiões onde era produzida. No entanto, nas últimas décadas, juntamente com o uso contínuo de bebidas tradicionais à base de erva-mate, também tem sido utilizada no desenvolvimento de alimentos, na indústria farmacêutica, química e de cosméticos.

Entre os estudantes participantes, as dificuldades encontradas pelos mesmos para sua participação no evento, foram a distância (5\%), disponibilidade de tempo (38\%) e não tiveram nenhuma dificuldade (56\%). Observou-se, assim que o tema abordado na palestra foi avaliado de suma importância, referindo-se uma das possibilidades que através do cultivo da erva-mate conter impactos ambientais, bem como sócio econômico e a sustentabilidade no meio rural. Nesse sentido, 90\% participariam novamente de outras palestras na mesma temática (Figura 5A). Observa-se que $82 \%$ dos estudantes não sentiram a necessidade de algum material suplementar, como por exemplo, panfletos (Figura 5B). Assim, a forma de abordagem do tema ao público, através de explanação oral com auxílio de apresentação em Power Point e vídeos baseados em entrevistas com pesquisadores e agricultores, facilitou o entendimento do tema sobre a erva-mate.
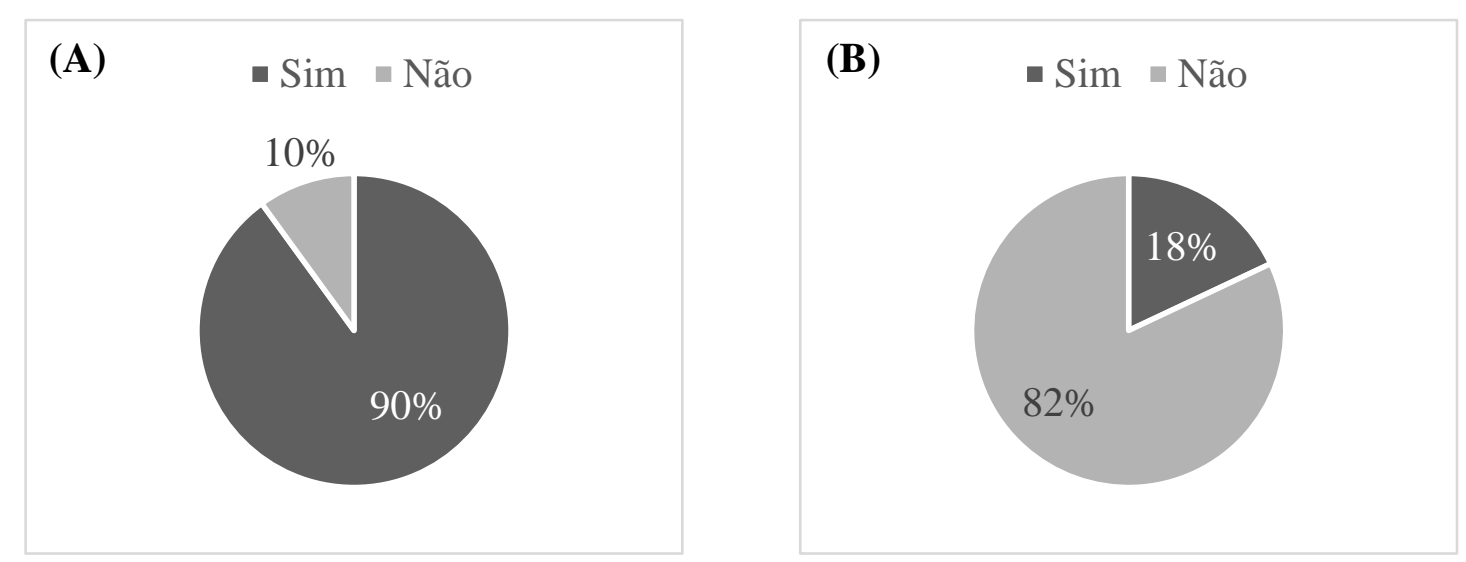

Figura 5 - Interesse dos estudantes na participação em outro evento (A) e necessidade de outros materiais suplementares (B), em Três Passos/RS, 2017. Fonte: Dados dos pesquisadores (2017).

Segundo, o produtor e proprietário da ervateira local Erva-Mate Celeiro Três Passos, que iniciou as atividades no ano de 1994, relata que optou em cultivar a erva-mate como opção de renda extra, e atualmente cultiva oito hectares, de forma economicamente muito rentável com Revista Extensão em Foco, nº 15, Jan/ Jul, p.108 - 119, 2018. 
a venda erva-mate processada para o chimarrão. Ainda, informa a intensão de ampliação da área cultivada com erva-mate, principalmente em áreas de solos degradados, local de ótima adaptação da cultura. Todavia, embora o RS estar buscando caminhos para o crescimento na produção da erva-mate, essa tarefa ainda apresenta muitos desafios, como por exemplo, a falta de matéria prima para a ervateira, relata o produtor. O produtor da ervateira também salienta a importância do cultivo da erva-mate, para e recuperação de áreas de solos degradados como um caminho para a preservação do meio ambiente.

Observou-se que o cultivo da erva-mate vem de encontro a soluções buscadas para a amenização dos problemas de preservação do meio ambiente nas propriedades rurais. Esse, é uma das causas mais preocupantes relacionadas com a preservação dos meios naturais, pois o homem depende exclusivamente deste para sua sobrevivência. Entende-se que os impactos sociais, econômicos e ambientais têm reflexos não somente no meio rural, mas também em toda a sociedade. Nesse sentido, o assunto deve acontecer no ambiente escolar com metodologia adequada, através da interação da família rural, comunidade em geral e dos meios de comunicação. A participação dos estudantes é de extrema importância, pois serão eles os sujeitos das mudanças do atual cenário social, econômico e ambiental. Por fim, a intencionalidade deste trabalho não é de encontrar somente respostas, mas também soluções sobre o tema, bem como refletir e incentivar práticas do cultivo da erva-mate envolvendo a inserção de propriedades rurais, buscando associar o econômico, social e a sustentabilidade ambiental.

\section{CONCLUSÕES}

O cultivo da erva-mate ainda é pouco difundido no município de Três Passos - RS. Após a realização das atividades nas escolas com as palestras, vídeos e distribuição de mudas, uma nova concepção foi atingida sobre o cultivo da erva-mate com os estudantes do ensino fundamental. Em síntese, através da cultura da erva-mate é possível diversificar e aumentar a renda familiar, e consequentemente o bem-estar das famílias, além da preservação de nascentes, recuperação de áreas degradadas e redução dos desmatamentos na região.

Existe a necessidade de novas ações sobre o cultivo da erva-mate e, com o envolvimento e ampliação das escolas rurais envolvidas, para desencadear uma sólida formação de opinião a respeito da valorização do meio ambiente. Para isso, salienta-se que o êxito da proposta, depende da necessidade de acesso as informações pela sociedade, através da formação de novos princípios com procedimentos voltados a recuperação e proteção do meio ambiente. 
Por fim, as crianças e os jovens serão os futuros atores sociais que definem sua identidade sociocultural e que podem remeter ações e valores para promover a melhoria na qualidade econômica, social e ambiental nas comunidades rurais, bem como difundir a consciência ambiental.

\section{REFERÊNCIAS}

ANTONIAZZI, Maria Salete. A cadeia produtiva da Erva-Mate, no Município de Três Passos/RS, Produção, Industrialização e a Comercialização. 2013. 56f. Trabalho de Conclusão ao Curso de Graduação Tecnológica em Desenvolvimento Rural - PLAGEDER, da Faculdade de Ciências Econômicas da UFRGS. Disponível em: <http://www.lume.ufrgs.br/bitstream/handle/10183/87414/000907881.pdf?sequence=1>. Acesso em: 11 out. 2016.

BAGGIO, Amilton João et al. Recuperação e proteção de nascentes em propriedades rurais de Machadinho-RS. Embrapa. Brasília, 2013. Tipo de publicação: Folhetos. Disponível em: $<$ https://www.embrapa.br/busca-de-publicacoes/-/publicacao/971488/recuperacao-e-protecaode-nascentes-em-propriedades-rurais-de-machadinho-rs >. Acesso em: 11 fev. 2017.

BERKAI, Dorival; BRAGA, Clóvis Airton. 500 Anos de História da Erva-mate. Editora Cone Sul. Porto Alegre, 2000. Livro, $1^{\text {a }}$ edição, p. 97.

BERNARDI, Estácio; CALDEIRA, Maria Fátima; NASCIMENTO, João Silvério. Identificação de fungos filamentosos em erva-mate (Ilex paraguariensis). Arquivos do Instituto Biológico, v.72, p. 489-493, 2005. Disponível em: <http://www.biologico.sp.gov.br/docs/arq/v72_4/bernardi.PDF>. Acesso em: 11 abr. 2017.

CARPENAZZI, Antônio; SANTAROSA, Ernani. Recuperação e proteção de nascentes. Portal EMBRAPA, 2016. Disponível em: 〈http://ainfo.cnptia.embrapa.br/digital/bitstream/item/141325/1/07-PGM-08-SUL.mp3>.

Acesso: 10 abr. 2017.

CORREA, Gracieli et al. Desenvolvimento de uma progênie biclonal de erva-mate em Machadinho, RS. Paraná: Embrapa/Florestas, 2011, 28p. (Série Documentos, 224). Disponível em: $\quad\langle$ https://www.ainfo.cnptia.embrapa.br/digital/bitstream/item/46075/1/Doc224.pdf $>$. Acesso: 25 jan. de 2017.

EMBRAPA. 2010. Rentabilidade econômica comparativa entre plantios florestais e sistemas agroflorestais com erva-mate, eucalipto e pinus e as culturas do feijão, milho, soja e trigo. Circular técnica, 26 ISSN 0101-1847 ... Colombo: EMBRAPA-CNPF, 1997. Disponível em: <https://ainfo.cnptia.embrapa.br/digital/bitstream/CNPF-2010/16592/1/circtec26.pdf>. Acesso em: 11 abr. 2017.

EMBRAPA. Cultivo da Erva-Mate. Sistemas de Produção, Embrapa, $1^{a}$ ISSN 1678-8281. Abr/2014, $\mathbf{2}^{\mathbf{a}}$ edição. Disponível em: $<$ https://www.spo.cnptia.embrapa.br/conteudo??p_p_id=conteudoportlet_WAR_sistemasdepro ducaolf6_1ga1ceportlet\&p_p_lifecycle=0\&p_p_state=normal\&p_p_mode=view\&p_p_col_id

Revista Extensão em Foco, nº 15, Jan/ Jul, p.108 - 119, 2018. 
=column-2\&p_p_col_count=1\&p_r_p_-76293187_sistemaProducaoId=3601\&p_r_p_996514994_topicoId=2901> Acesso em: 10 abr. 2017.

IBGE - Instituto Brasileiro de Geografia e Estatística. Produção Agrícola Municipal Lavoura Permanente. Disponível em: 〈http://cod.ibge.gov.br/1NE8Y〉. Acesso em: 27 julho, 2017.

MAURINA, Adilson. O êxodo rural e as transformações ocorridas na comunidade rural de Veado Pardo, município de Marau - RS. Porto Alegre. 2011. Trabalho de Conclusão de Curso de Graduação Tecnológica em Desenvolvimento Rural - PLAGEDER, da Faculdade de Ciências Econômicas da UFRGS. 41p. Disponível em: <http://www.lume.ufrgs.br/bitstream/handle/10183/54665/000855385.pd $f$ >. Acesso em: 13 abr. 2017.

OLIVEIRA, Sibele Vasconcelos; WAQUIL, Paulo Dabdab. Dinâmica de produção e comercialização da erva-mate no Rio Grande do Sul, Brasil. Ciência Rural, v.45, p.750756, 2015. Disponível em: 〈https://doi.org/10.1590/0103-8478cr20140276>. Acesso em: 20 mar. 2017.

PASINATO, Raquel. Aspectos etnoentomológicos, socioeconômicos e ecológicos relacionados à cultura da Erva-mate (Illex paraguariensis) no município de Salto do Lontra, Paraná, Brasil. 2003. 112f. Dissertação de Mestrado à Escola Superior de Agricultura Luiz de Queirós, Piracicaba, São Paulo, Brasil. Disponível em: 〈www.teses.usp.br/teses/disponiveis/91/91131/tde-29072004.../raquel.pdf〉. Acesso em: 19 fev. 2017.

SIGNOR, Pablo; GOMES, Gabriela Schmitz; WATZLAWICK, Luciano Farinha. Produção de erva-mate e conservação de Floresta com Araucária. Pesquisa Florestal Brasileira, v.35, n.83, p.199-208, 2015. Disponível: 〈http://dx.doi.org/10.4336/2015.pfb.35.83.898>. Acesso em: 21 mar. 2017.

TRÊS PASSOS - R.S. 2011. Programa Semeando Educação e Saúde na Agricultura Familiar. Documentos. Disponível em: <http://www.trespassos-rs.com.br>. Acesso em: 15 jun. 2016.

VIEIRA, Timni 2012. Viabilidade econômica da cultura de erva-mate (Ilex paraguariensis) em áreas de reserva legal no Paraná. Dissertação de Mestrado em Engenharia Florestal. Universidade Federal do Paraná. Curitiba, 2012. 139p. Disponível em: $<$ http://acervodigital.ufpr.br/bitstream/handle/1884/32265/R\%20-\%20D\%20\%20TIMNI\%20VIEIRA.pdf?sequence=1\&isAllowed=y >. Acesso em: 10 abr. 2017. 